This item was submitted to Loughborough's Research Repository by the author.

Items in Figshare are protected by copyright, with all rights reserved, unless otherwise indicated.

\title{
Machine vision in conjunction with a knowledge-based system for semi- automatic control of a gravure printing process
}

PLEASE CITE THE PUBLISHED VERSION

PUBLISHER

Professional Engineering Publishing / @ IMECHE

VERSION

VoR (Version of Record)

LICENCE

CC BY-NC-ND 4.0

\section{REPOSITORY RECORD}

Brown, Neil, Michael R. Jackson, Robert M. Parkin, and P.E. Bamforth. 2019. "Machine Vision in Conjunction with a Knowledge-based System for Semi-automatic Control of a Gravure Printing Process". figshare. https://hdl.handle.net/2134/4734. 
This item was submitted to Loughborough's Institutional Repository (https://dspace.lboro.ac.uk/) by the author and is made available under the following Creative Commons Licence conditions.

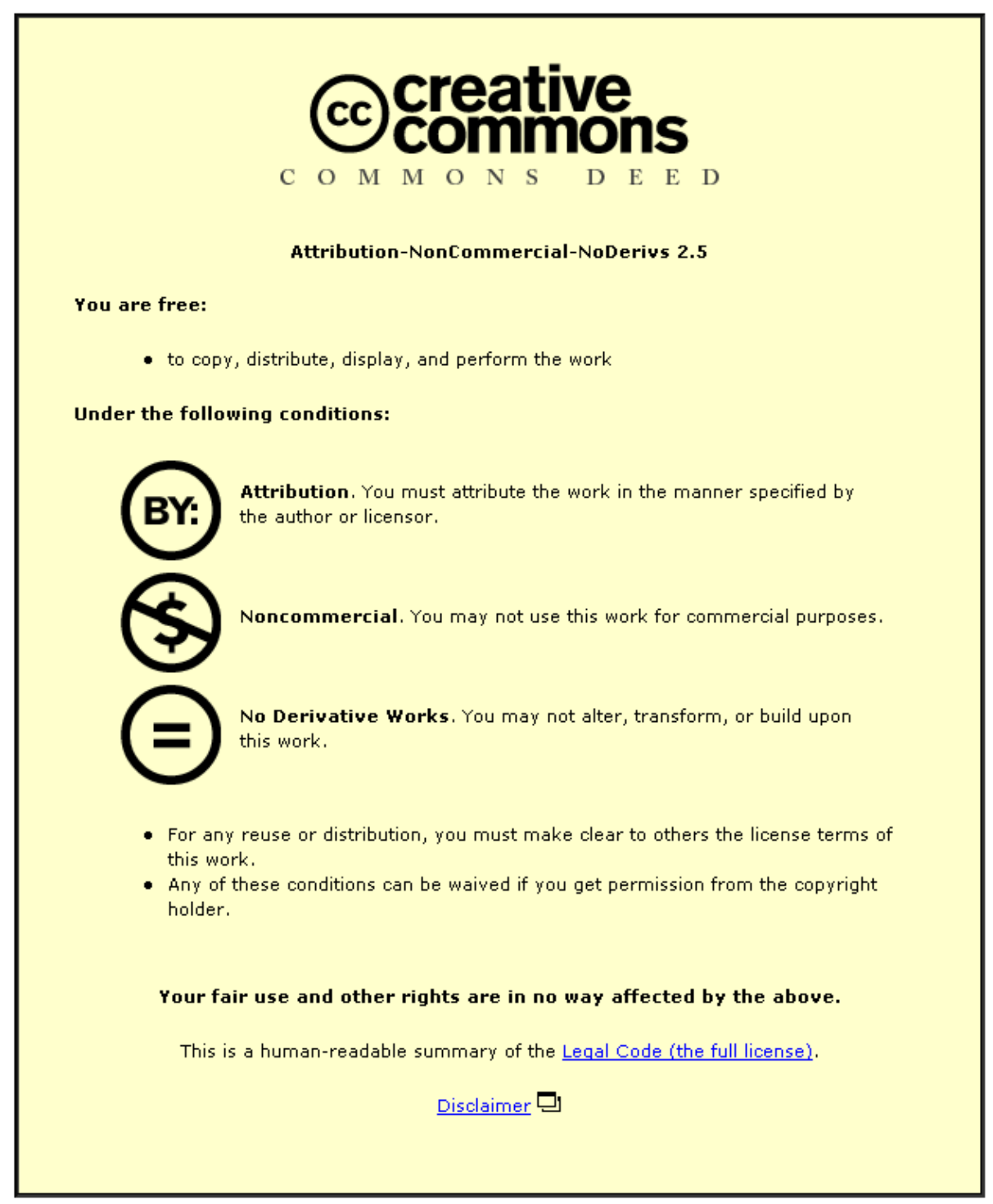

For the full text of this licence, please go to: http://creativecommons.org/licenses/by-nc-nd/2.5/ 


\title{
Machine vision in conjunction with a knowledge-based system for semi-automatic control of a gravure printing process
}

\author{
N Brown*, M R Jackson, R M Parkin and P E Bamforth \\ Mechatronics Research Group, Wolfson School of Mechanical and Manufacturing Engineering, Loughborough \\ University, Loughborough, UK
}

\begin{abstract}
This paper describes the work carried out to produce an automated print inspection system, which was developed on a gravure printing press within the wall-covering printing industry. The project aim was to produce a system that could continuously monitor the gravure printing process, by examining printed material using machine vision, and then by using a fuzzy knowledgebased system to interpret the machine vision system output and to make recommendations to an operator as to how to correct the process with simple text-based suggestions, avoiding printing of scrap material.
\end{abstract}

Keywords: mechatronics, gravure, machine vision

\section{NOTATION}

$L, a, b \quad$ Commission Internationale de l'Éclairage (CIE) standard colour space coordinate ( $L^{*} a^{*} b^{*}$ system) (CIE standard units)

$L_{1}, a_{1}, b_{1}, L_{2}, a_{2}, b_{2}$ colour space sets where the subscripts 1 and 2 denote different sets for comparison (unitless)

$\Delta E \quad$ CIE standard colour difference (CIE standard units)

$\Delta E_{\mathrm{t}} \quad$ tolerance of colour drift (CIE standard units)

$\Delta L \quad$ CIE $L$ value drift (CIE standard units) Other $\Delta$ prefixes difference between a stored print feature from a master sample, with acceptable print quality, and the current sample

\author{
Subscripts to $\Delta f$ (print features) \\ 1 haze (per cent) \\ 2 white hole content (white hole pixel count \\ divided by image total pixel count) \\ boundary roughness (per cent) \\ blotchiness (per cent) \\ rivering (dot size in direction of print when \\ over $0.3 \mathrm{~mm}$ ) \\ streaking \\ dot size (in direction of print) \\ dragout
}

\section{Subscripts to $s$}

$\begin{array}{ll}1 & \text { ink viscosity } \\ 2 & \text { impression pressure (turns) } \\ 3 & \text { web speed }(\mathrm{m} / \mathrm{s})\end{array}$

\section{INTRODUCTION}

for publication on 20 July 2004

* Corresponding author: Mechatronics Research Group, Wolfson School of Mechanical and Manufacturing Engineering, Loughborough University, Loughborough, Leicestershire LE11 3TU, UK. E-mail: N.Brown@ lboro.ac.uk

When printing a new design for the first time or printing an existing design with new colours for the first time (a new colourway), a master sample is produced. A typical

Proc. Instn Mech. Engrs Vol. 218 Part I: J. Systems and Control Engineering 
gravure printing machine is shown in Fig. 1. Operators making subsequent print runs must refer to this master sample in order to produce a similar result [1]. When this happens, a trial print is made on the machine, which is then stopped. The printed sample is compared manually with the master sample, and machine adjustments are made in order to produce a match [2]. Visual assessment of print quality in this way suffers from several main disadvantages. Manual inspection relies on human colour vision, which is quite inconsistent [3-5]. Its variability could mean that no two print operators reach the same conclusion on whether colours are matched. Gravure printed images are built up from a number of tiny dots, produced by ink cells typically $80 \mu \mathrm{m}$ in size, as shown in Fig. 2.

These ink cells are carried in a specially manufactured cylinder, one cylinder being dedicated to each colour used in the design. Since these dots are almost invisible

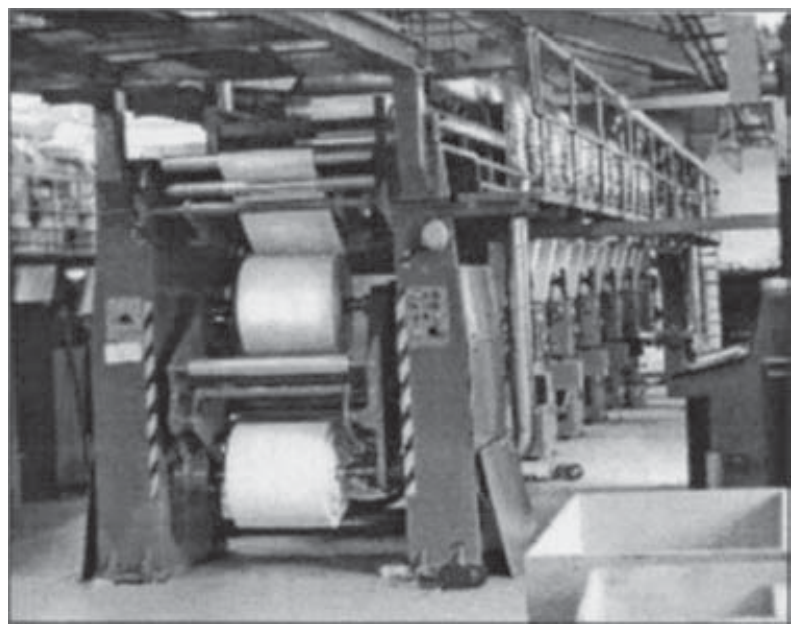

Fig. 1 Gravure press

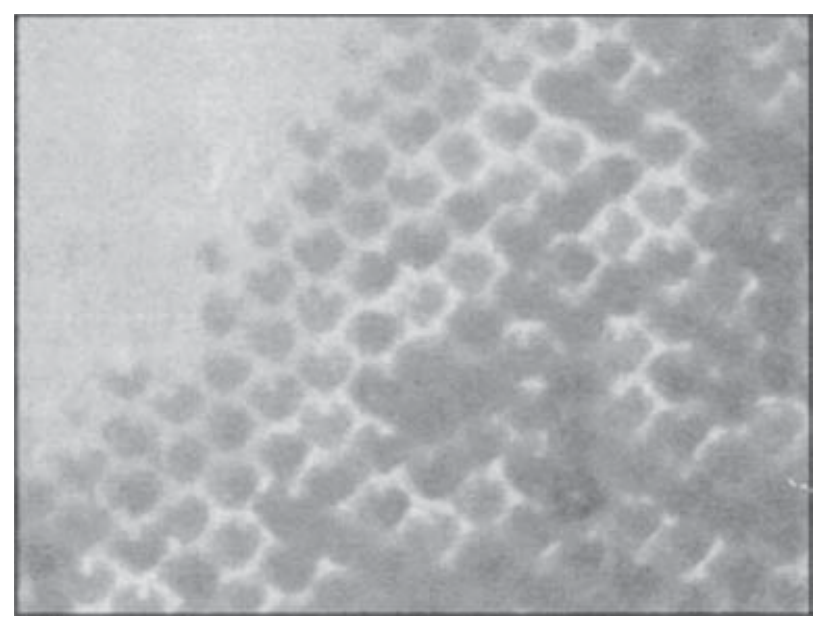

Fig. 2 Gravure dots to the naked eye, appraisals of print quality are made from the whole image, a highly subjective process. In order to take samples to print off line, the machine must be stopped, which introduces further variability and uncertainty into the printing process. Following manual inspection, the machine is restarted and machine adjustments are made to try to correct print colour and quality. Print adjustment is entirely unguided, except by human intuition; it is a manual process that suffers from the following disadvantages.

Operators have no set method of machine adjustment, some preferring to alter a different main process variable to others. The adjustments being made are based on operator experience-indeed, a 'feel' for the process. Because of this, printing has been referred to as a 'black art'. Different shifts may have preferred machine settings and, in extreme cases, a new shift may alter controls on a machine that is already printing acceptable material.

To compound the apparently mysterious nature of print machine adjustment, many machine controls may not be fitted with any form of readout, and so successful machine adjustments are difficult to document. The ideal goal would be to have a printing process that automatically sets up and never produces any defective product. An intermediate step is a system that keeps the human operator 'in the loop', but can inspect the printed web on line and detect changes in print quality before they become visible to the human eye as the printing process may 'drift' away from ideal settings. Thus, the printing of scrap may be avoided. This paper describes the fundamentals of this 'human-in-the-loop' system.

\subsection{System overview}

The solution developed was to use an imaging system to examine the dot features produced by the gravure process, in conjunction with a spectral imaging system, which provides a means for colour checking on line to high precision. A knowledge-based system (KBS) is then used to analyse the resultant data to infer process variables and to make recommendations for process control. Original research carried out to build this system involved the development of the following key technologies:

(a) first known non-contact spectral imaging system to examine moving material;

(b) first imaging system to provide process health data from gravure printed dots on line;

(c) first KBS to infer printing process variables such as web speed and impression pressure from the printed web.

The context level operation of the integrated system is summarized in Fig. 3. 


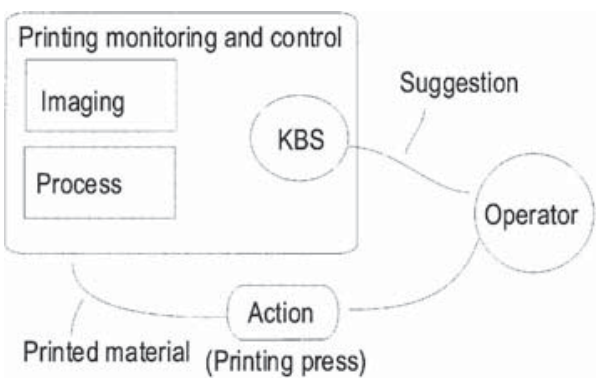

Fig. 3 Context level system overview

\subsection{The gravure process}

A schematic diagram demonstrating the gravure printing process is shown in Fig. 4. The process variables of rotogravure colour printing include $[\mathbf{2}, \mathbf{6}]$ :

(a) process parameters of printing equipment: web speed (the speed of the printed web through the machine), impression pressure and doctor blade setting;

(b) characteristics of components of printing equipment: cylinder and a doctor blade (a device used to remove excess ink from the print cylinder);

(c) ink properties: viscosity, elasticity, surface tension, solvent type and colour;

(d) substrate properties: surface treatment, surface finish properties, opacity and colour;

(e) environmental conditions: temperature and humidity.

During machine trials the doctor blade set-up (projection and angle) was standardized, and viscosity, while measured and corrected on a regular basis, was controlled via suggestions from the KBS. Viscositymeasuring and control machines had been tested at the factory but had proven unreliable and difficult to clean (an important consideration when short production runs are the norm and ink colours are changeable from one design to another, i.e. not 'process colours'). It was found that, by fixing the doctor blade angle, this could be eliminated as a process variable (since print operators had previously not used a standard setting, the doctor blade angle would affect the final print). The doctor blade

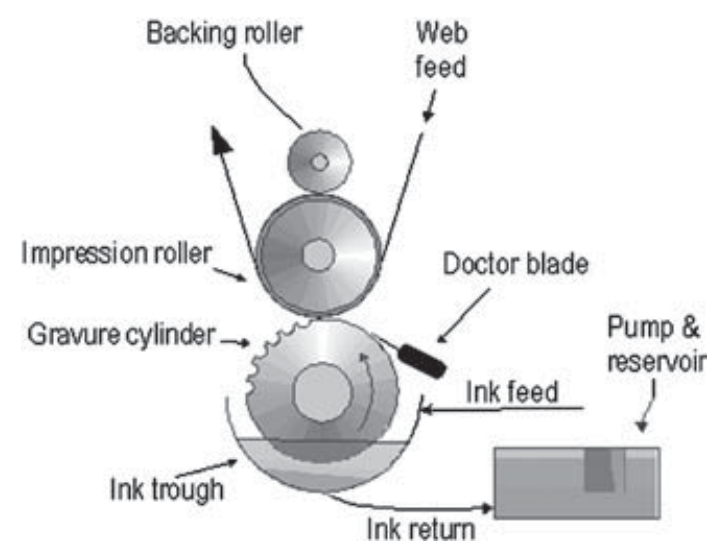

Fig. 4 Gravure process pressure could also become standardized in this way. Pneumatic loading cylinders were not used to control blade pressure, since these worked against hard stops; the final adjustment was made by a screw thread. Substrate properties were not found to vary significantly, although substrate colour is calibrated for on-line printing by the colour measurement system. To this end, the impression pressure, web speed and viscosity are the only output process variables needed by the KBS to control variability reliably in the printing process.

\section{IMAGING SYSTEM}

The Commission Internationale de l'Éclairage (International Commission on Illumination) (CIE) standard of colour measurement was chosen as the standard for porting of colour data from the printing press and is already widely used for ink colour checking [5]. Standard CIE mathematics has been coded into software to allow conversion from spectral data to colour information [6]. The CIE colour space is an industry standard method of representing colour. To determine the absolute difference between two colours in the Lab colour space the following equation [4] was used:

$$
\Delta E=\sqrt{\left(L_{1}-L_{2}\right)^{2}+\left(a_{1}-a_{2}\right)^{2}+\left(b_{1}-b_{2}\right)^{2}}
$$

Conventional colour video systems have been used to good effect for precision colour measurement where colour differences are greater than those employed in printing [7-9]. The conventional red-green-blue (RGB) system suffers from two shortcomings. Firstly, the conversion of colour information from an RGB system to CIE $L a b[10] X Y Z$ tristimulus values is arbitrary; also some colour data may not be acquired since the RGB colour space cannot map all visible colour. The other shortcoming of RGB-based colour video systems is that quantization produced by analogue-to-digital conversion often exceeds $1 \Delta E$ (the generally accepted limit for human colour vision) for 8 and 10 bit systems. Highresolution print imaging has been achieved using a flatbed scanner, but this method is unsuitable for on-line measurement. The approach therefore taken was to utilize a non-contact spectrophotometer, called the Imspector [6]. This device uses a prism-grating-prism component to convert colour information into spectra which are then projected on to the charge-coupled device of a conventional monochrome area scan camera. Tone blocks, an existing feature, are areas of solid and graded print printed at the edge of the web and are utilized for spectral colour measurement. When the printed material leaves the machine, the selvedge containing the tone blocks is trimmed off. Colour measurement requires the translation of spectral data to relevant points in the CIE colour space, the mathematics of which has been described by three of the present authors and a co-worker $[\mathbf{1}, \mathbf{6}]$. Reference to Fig. 5 will show the data flows of the 


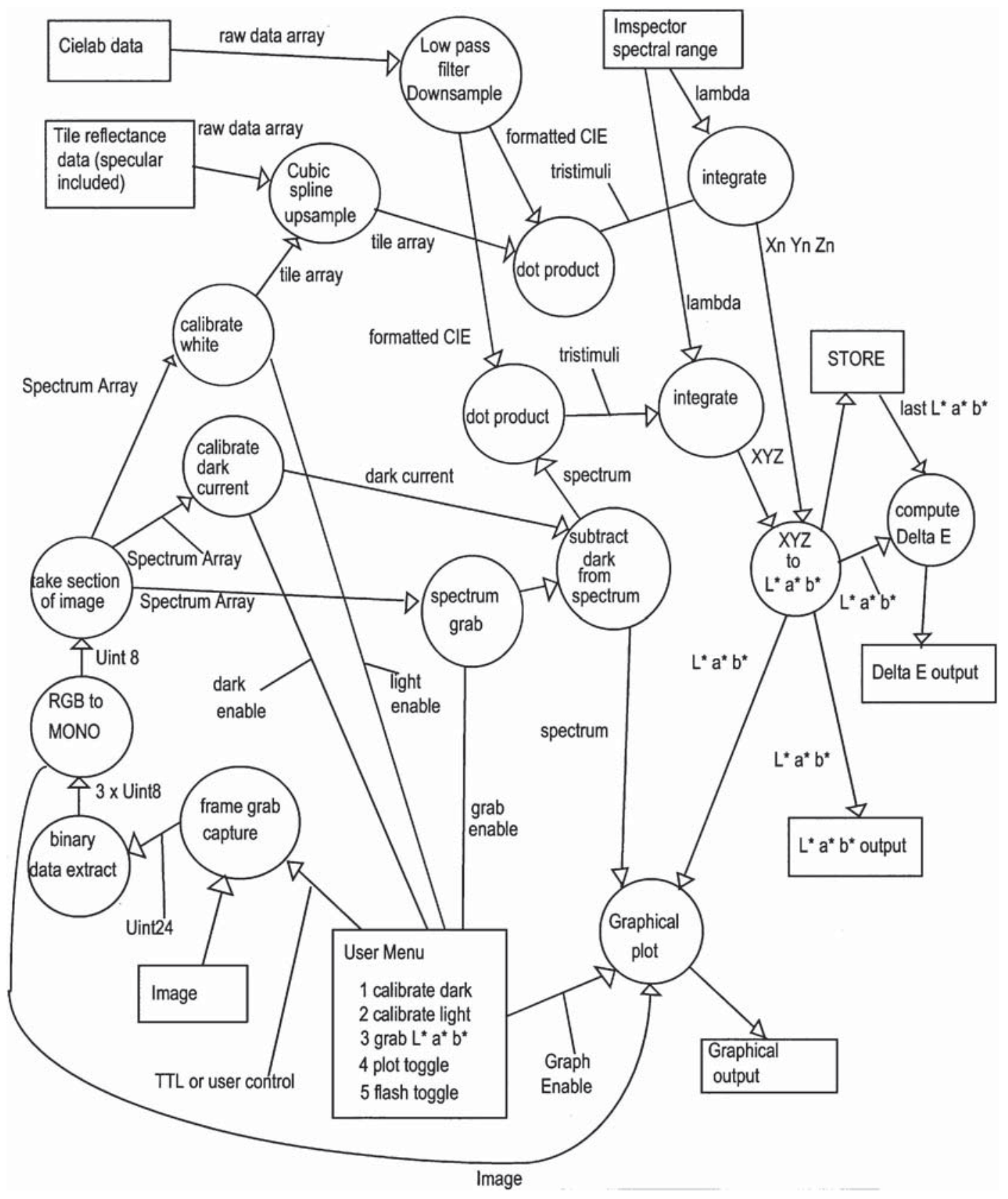

Fig. 5 Colour measurement system data flows

software implementation. Table 1 shows a summary of the colour data that are thus ported from the imaging system to the KBS. Weights are applied to the dot feature and colour data after processing, in order to enable the KBS to make a suggestion. The full description of how this process is carried out has been described in reference [13].

\subsection{Imaging hardware}

Figure 6 shows the layout of the image-grabbing apparatus, whereby the colour sample is converted to spectral data by the Imspector, the resultant image being captured by a conventional monochrome area scan camera. Dot features are captured with a similar camera.

Table 1 Colour data ported to KBS

\begin{tabular}{lll}
\hline Feature & Object & Definition \\
\hline Substrate white reference & Zero tone (paper) & CIE $L^{*} a^{*} b^{*}$ coordinates \\
Substrate-ink interaction & $50 \%$ tone & CIE $L^{*} a^{*} b^{*}$ coordinates \\
Ink colour & $100 \%$ tone & CIE $L^{*} a^{*} b^{*}$ coordinates \\
\hline
\end{tabular}




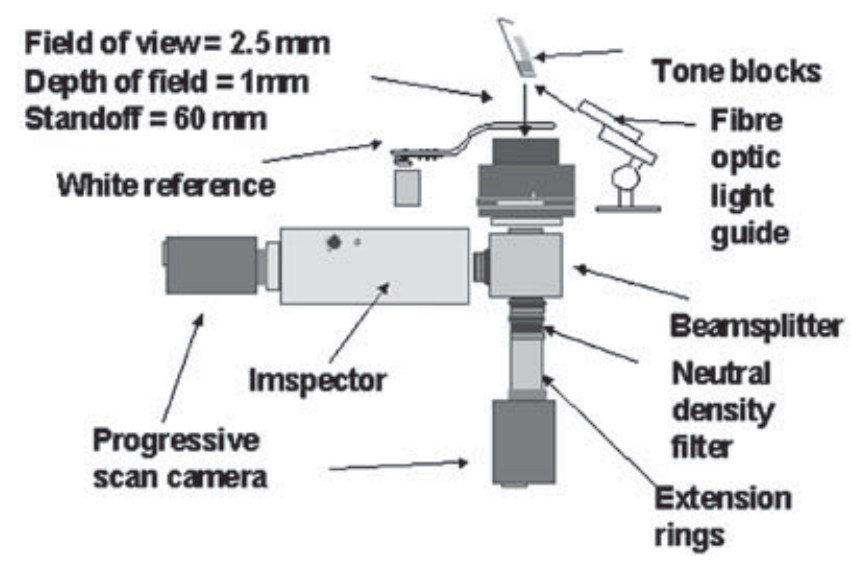

Fig. 6 Imaging apparatus

A personal-computer-based frame grabber is used for image capture. Colour inspection and dot feature inspection components are arranged such that the same section of web is examined. The fibre-optic light guide carries an optical cable to deliver illumination from a xenon flash, which combines a broad spectrum, long life (compared with halogen), intense illumination and motion 'freezing'. To this effect, a $2 \mathrm{~J}$ pulse xenon flash tube is used to illuminate the area of interest (a $2.5 \mathrm{~mm} \times$ $2.5 \mathrm{~mm}$ square region, which is used for spectral colour imaging and dot feature examination simultaneously). The flash time is $1.25 \mu \mathrm{s}$, but the flash profile limits illumination smear to $2.5 \mu \mathrm{m}$ at a web speed of $2 \mathrm{~m} / \mathrm{s}$.

\subsection{Gravure dot features}

Examination of the tone blocks printed at the edge of the web shows that examination of a combination of tone levels of 25 and 50 per cent works reliably for identification of print defects, primarily since distinct dots are visible at 25 per cent, allowing the imaging system to measure features such as dot size accurately. Typical dot features are shown in Figs 7 to 12, and cross-references are included with respect to Table 2, for clarification where necessary.

In practice, some 200 dots are recognized and labelled to provide a representative sample. Images displayed here feature a reduced dot count but show all the main dot features for print defects that must be recognized by the system. The detailed description of how the imaging software works has been published by three of the present authors [11].

Figure 7 shows a relatively clean print with few defects. A print produced by such dots is deemed acceptable by the manufacturer. Figure 8 shows 'white holes' (Table 2, third feature), i.e. an area of printed dots where some blockage of the printing cells that carry the ink is taking place. While the dots produced may not affect print quality to any noticeable extent, extrapolation of these features leads to a drop in print coverage, which must be detected. The effect shown in Fig. 9 is known as rivering (Table 2, sixth feature) and is a defect caused

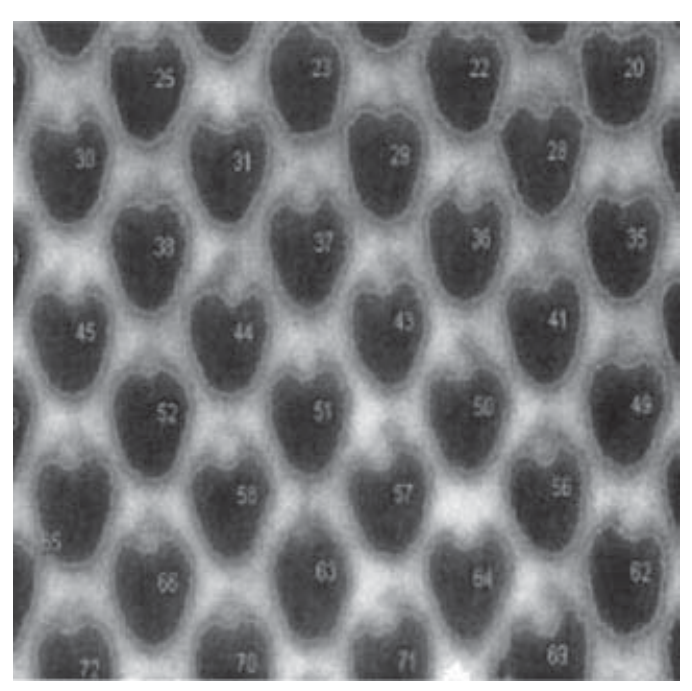

Fig. 7 Good features

Table 2 Dot feature data passed from the imaging system to the KBS

\begin{tabular}{|c|c|c|}
\hline Feature & Object & Definition \\
\hline Dragout & Dot $(25 \%$ tone level $)$ & $\begin{array}{l}\mathrm{d} x / \mathrm{d} y \\
\mathrm{~d} x \text { and } \mathrm{d} y<0.34 \mathrm{~mm}\end{array}$ \\
\hline Haze & Points with grey scale lower than average ( $25 \%$ tone level) & $\begin{array}{l}\left(G-G_{\text {substrate }}\right) /\left(G_{\text {ink }}-G_{\text {substrate }}\right) \\
\quad \text { where } G=\text { grey level on a scale } 0-255\end{array}$ \\
\hline White hole size & $\begin{array}{l}\text { Closed small shape with grey scales of all internal points lower than } \\
\text { average ( } 25 \% \text { tone level) }\end{array}$ & $\mathrm{d} x$ and $\mathrm{d} y<0.04 \mathrm{~mm}$ \\
\hline Boundary roughness & Dot $(25 \%$ tone level $)$ & $\begin{array}{l}\text { Percentage of image to fall through } \\
\text { a } 20 \times 20 \text { pixel convolution filter }\end{array}$ \\
\hline Blotchiness & $\begin{array}{l}\text { Elongated dot where } 1 \mathrm{~mm}>\mathrm{d} x>0.34 \mathrm{~mm} \text { and } \mathrm{d} y<0.34 \mathrm{~mm} \text {, when } \\
\text { examining } 25 \% \text { tone level }\end{array}$ & $\operatorname{Max}[\operatorname{area}$ or $(\mathrm{d} x \mathrm{~d} y) / 2]$ \\
\hline Rivering & Large river-like shapes ( $50 \%$ tone level) $\mathrm{d} x>1 \mathrm{~mm}$ and $\mathrm{d} y>0.34 \mathrm{~mm}$ & $\operatorname{Max}[\operatorname{area}$ or $(\mathrm{d} x \mathrm{~d} y) / 2]$ \\
\hline Streaking & $\begin{array}{l}\text { Long lighter/darker lines, dashed or continued ( } 25 \% \text { tone level) } \\
\text { For continued dark lines, } \mathrm{d} x>1 \mathrm{~mm} \text { and } \mathrm{d} y<0.34 \mathrm{~mm}\end{array}$ & Length of dot tail \\
\hline
\end{tabular}




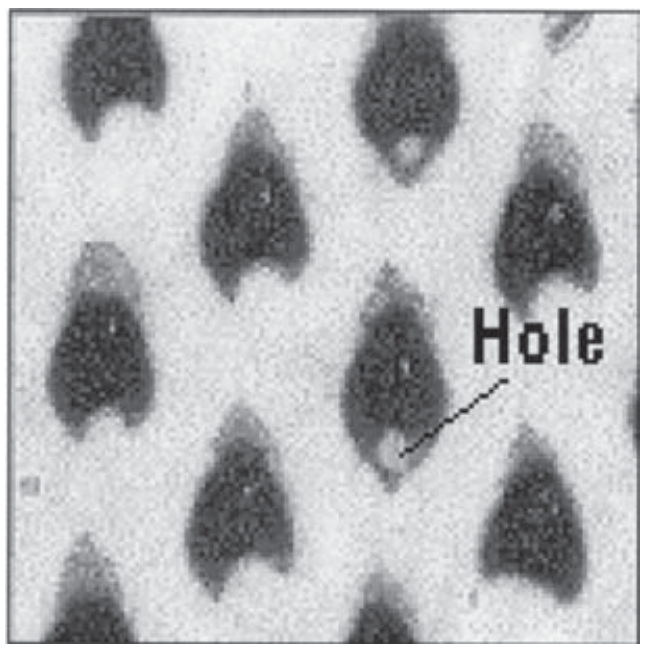

Fig. 8 Hole size

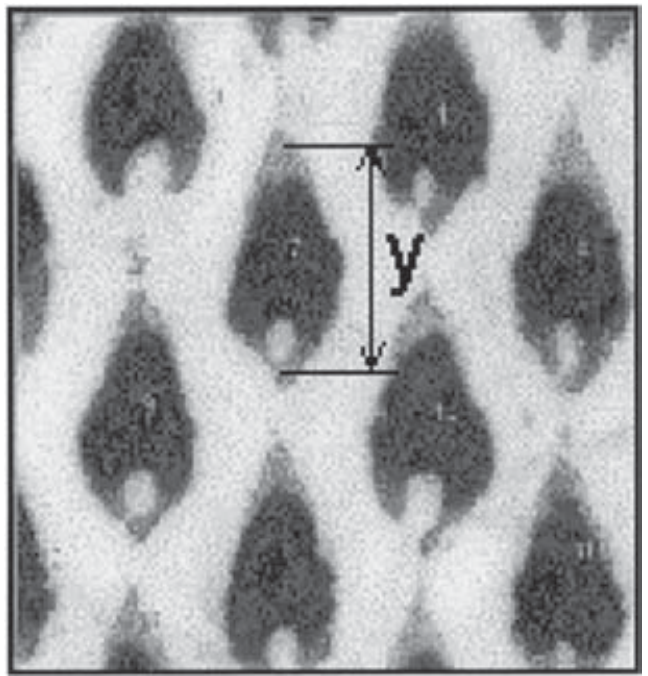

Fig. 9 Dot size-rivering example

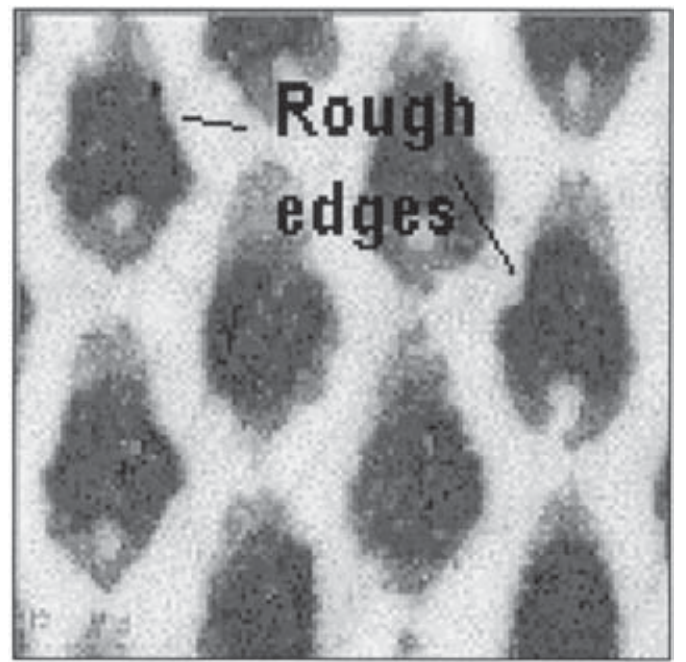

Fig. 10 Boundary roughness

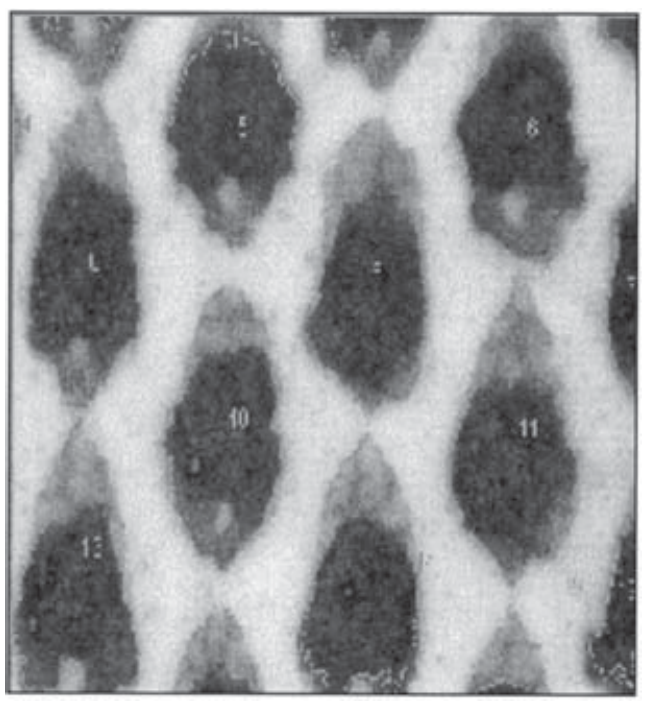

Fig. 11 Blotchiness

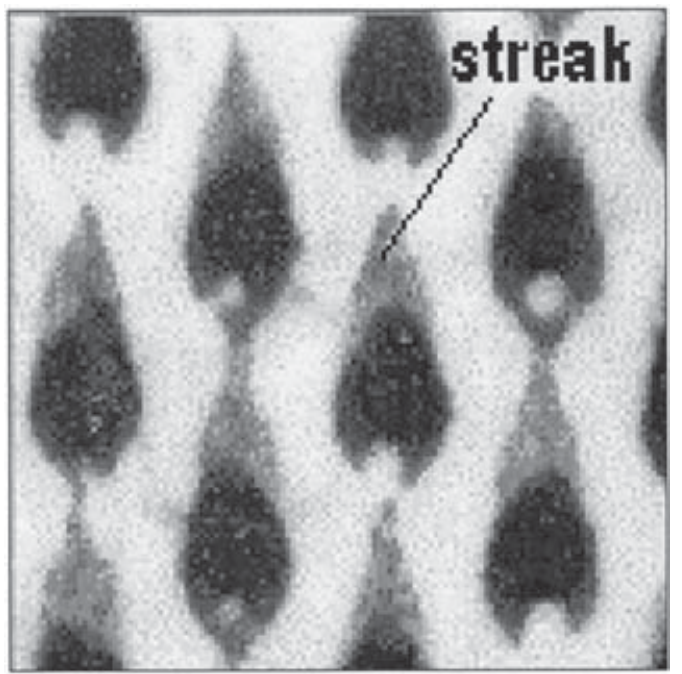

Fig. 12 Streaking example

by ink flow across the paper from one gravure cell to another. This is an exaggerated form of dragout, an elongation of a dot, as described in Table 2, first feature. Boundary roughness (Table 2, fourth feature), where the dots are not printed cleanly, is shown in Fig. 10 and is used as an additional tool for detection of printing faults; it may be caused, for example, by low viscosity. Blotchiness (Table 2, fifth feature) is an exaggerated condition, often due to ink viscosity drop which occurs less often but must be detectable; it is illustrated in Fig. 11. Streaking (Table 2, seventh feature) is where elongated dots begin to connect and is shown in Fig. 12. All of these features must be numerically represented, although indirect representation is acceptable, in order to control the printing process. A summary of data passed to the KBS for dot features is shown in Table 2. It will be noticed that dot features may appear large in size, when 
compared with other printing methods, but these dimensions are not unusual in the gravure printing of wall coverings.

\section{KNOWLEDGE-BASED SYSTEM}

The KBS logs process parameters such as colour, dot features, web speed and ink viscosity (this process variable needs to be entered manually only at the start of a production run), in order to evaluate process health. After acquiring data from the imaging system, the KBS analyses colour drifts and dot feature drifts. If any of these drifts goes beyond tolerance, the KBS will conduct the following diagnosis. When colour drift at 100 per cent tone is found to be beyond tolerance, which is known to be caused by a drift in ink colour, the KBS will instruct the user on how to change the ink viscosity. However, when colour drift at 50 per cent tone and/or dot feature drifts are found to be beyond tolerances, the KBS will provide suggestions for the adjustment of process variables such as impression pressure. An early implementation of the system has been described by Peng et al. [12]. At the time, it was discovered that, for machines set up to a fixed procedure, dot feature parameters and colour may be controlled by adjusting only the process parameters of impression pressure, web speed and viscosity. Simplified KBS operation is as follows:

1. Compare the colour of the current sample with the master sample, using data from the spectral imaging system.

2. If colour drift is beyond a set tolerance, check the dot features from the imaging system; otherwise return to step 1.

3. Apply the fuzzy kernel to decode the dot features.

4. Make a process adjustment recommendation to the print machine operator.

5. Return to step 1 .

\subsection{Knowledge-based system fuzzy kernel for dot feature and colour analysis}

In order to produce a decision matrix $\mathbf{S}$ to analyse dot feature drift and correct for process defects, the kernel of the KBS takes the form
The $8 \times 3$ (probability) matrix shown in equation (2) contains probabilities of process variables affecting dot features and was produced during process experiments on the gravure press, producing printed blocks of graded colour using a test cylinder (step cylinder) by establishing the probability that a certain dot feature, e.g. rivering, would be produced by a known, but not necessarily quantifiable, change in one of the three key process variables. For example, the probability that a decrease in viscosity will lead to an increase in dot size may be high. The constants within the matrix were derived from extensive experimentation using the Cobden-Chadwick gravure press. The software checks the print features against those taken from a stored master sample for each print run and, if process parameters drift over thresholded values, typically 10 per cent drift, the fuzzy kernel is implemented to produce a suggestion matrix $\mathbf{S}$, which is used to generate suggestions for the print machine operator. The operator is able to follow the instructions generated by the KBS, and the print run returns to normal. Experimentation has proved that the system is able to spot and make recommendations to correct potential process drift well before any printed defects are visible to the human eye.

A decision matrix is produced on the basis of colour drift as in the following equation, with a simpler probability matrix:

$$
\mathbf{S}=-\left(\begin{array}{c}
0.11 \\
-0.629 \\
0.676
\end{array}\right)\left(\frac{\Delta E}{\Delta E_{\mathrm{t}}} \frac{\Delta L^{\prime}}{\left|\Delta L^{\prime}\right|}\right)
$$

Both suggestion matrices are weighted as shown in Fig. 13 and summed by the process parameter, so that a $1 \times 3$ output decision matrix is produced. An example decision matrix is

$$
\mathbf{S}=\left(\begin{array}{c}
0.54 \\
-0.61 \\
0.2
\end{array}\right)
$$

The (unitless) decision matrix is straightforward to decode, referring to the matrix (4); the central figure of -0.61 shows the strongest suggestion strength and is

$$
\mathbf{S}=\left(\begin{array}{c}
s_{1} \\
s_{2} \\
s_{3}
\end{array}\right)=\left(\begin{array}{cccccccc}
0.333 & 0.111 & 0.778 & -0.778 & 1 & 0 & -0.778 & -0.243 \\
-0.747 & 0.602 & 0.077 & -0.14 & 0.244 & 0.009 & 0.439 & 0.43 \\
0.387 & -0.108 & 0.171 & 0.104 & -0.306 & 0.023 & -0.36 & -0.243
\end{array}\right)\left(\begin{array}{c}
\Delta f_{1} \\
\Delta f_{2} \\
\Delta f_{3} \\
\Delta f_{4} \\
\Delta f_{5} \\
\Delta f_{6} \\
\Delta f_{7} \\
\Delta f_{8}
\end{array}\right)
$$




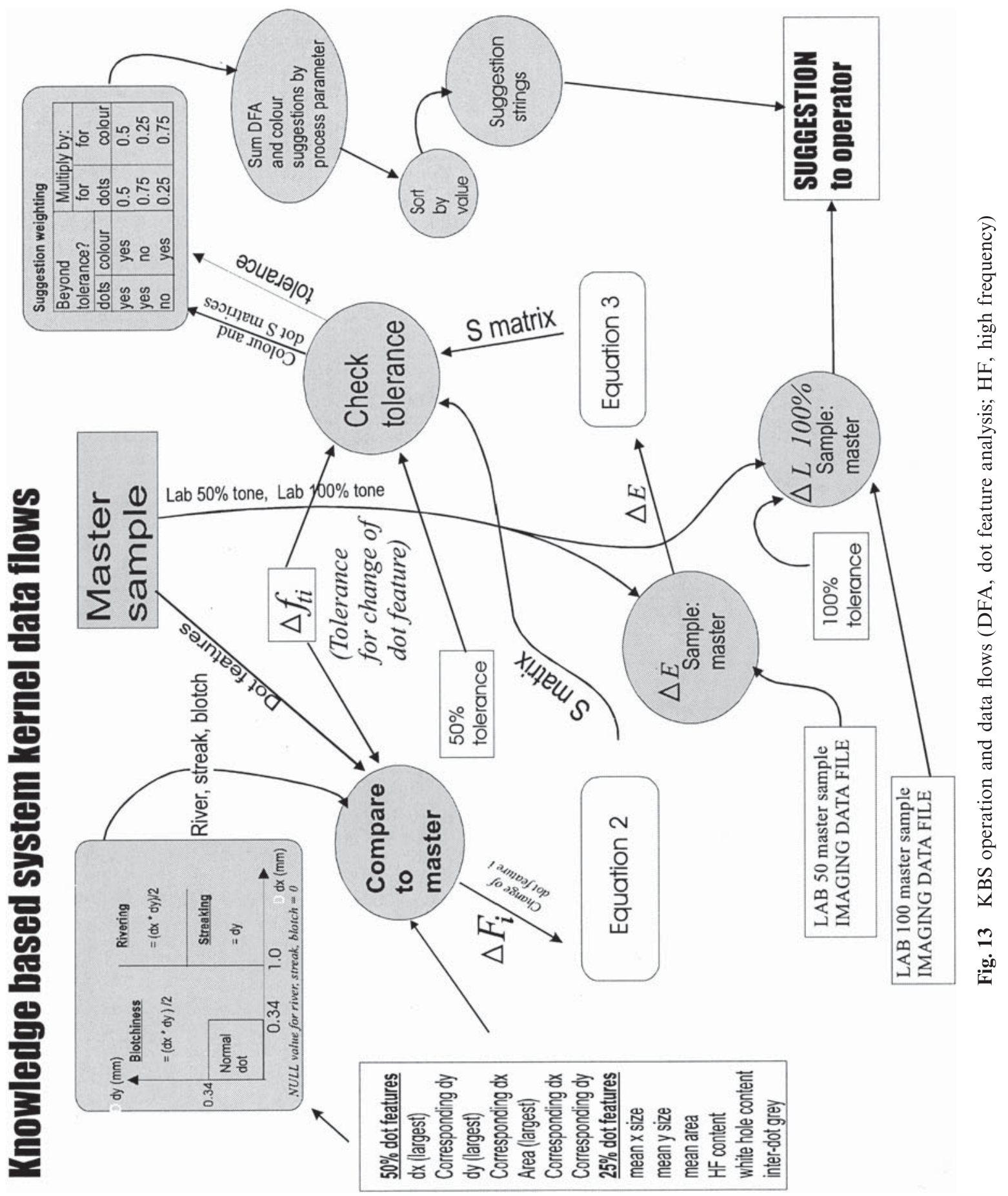


negative, and so the first recommendation to the operator will be to reduce the impression pressure. The second highest suggestion strength is 0.54 , for ink viscosity to be increased. This suggestion will also be put to the operator. It is not necessary to tell the operator of the third strongest suggestion. Suggestions to the operator appear as phrases in English, e.g. 'Check to see whether viscosity has dropped'. The data flows for the KBS software are shown in Fig. 13.

\section{RESULTS}

\subsection{Imaging system}

A statistical analysis of the experimental results for colour drift and device sensitivity, where the highest standard deviation (SD) for examination of the same colour is obtained with the Gretag SPM 50 spectrophotometer, is shown in Table 3. This could be accounted for by the $0-45^{\circ}$ illumination method, which is less stable to surface geometry than an integrating sphere. A lower $\mathrm{SD}$ is achieved using the Imspector, which averages spectra obtained from five sample points during each image grab, making colour acquisition more stable. The use of an integrating sphere gives a marginally more stable result for the Datacolor Microflash than for the Gretag SPM 50. When examining the gain of the devices when subjected to natural variations in the printing process, although the natural SD of the device is acknowledged, a difference is seen in results for colour drift measurement, for each device, measuring the same samples. An indication of the sensitivity of each device to colour variations (also describable as gain in $\Delta E$ ) between sample pairs may thus be provided. This enables the performance of the Imspector to be considered further. The machine trials thus undertaken showed that the Imspector has the lowest apparent gain for natural deviation in the printed colour, and the Datacolor Microflash has the largest.
It must be remembered that absolutes are not compared; i.e. no spectrophotometer can provide a concrete datum for colour measurement against a standard reference in, for example, the same way as a voltmeter or micrometer. However, all systems are measured within the same colour space, with the same method of processing spectral data, so that relative performances can be compared. The natural background noise of each device limits sensitivity to colour change, and the ratio of the natural variation of the printing process to this background noise can be used to determine useful colour drift gain for each device (for comparative purposes only, these results cannot be viewed in isolation and are not applicable to arbitrary points in the colour space). The best signal-to-noise performance is achieved using the Datacolor Microflash, with the Imspector's performance falling closer to that of the Microflash than the Gretag SPM 50. This is due to the low internal drift of the Imspector, making it more stable than the integrating sphere device. By placing the performance of the Imspector between two industry standard devices it can be seen that the colour measurement system developed herein is not only of adequate performance to provide data drive for the KBS, but also a potential competitor with conventional spectrophotometers in terms of performance.

Table 4 represents the expected output from the dot feature identification software, using the image shown in Fig. 7 as the reference sample. The expected changes in certain features of the printed dots are shown, based upon manual checking with a macroscope, e.g. the mean pixels per dot for a given change in dot feature. The presence of a greater number of negative or positive symbols indicates the magnitude of the expected output from the imaging software. The number of positive or negative symbols shown denotes the magnitude of the expected increase or decrease in software output variable value. Table column content is explained as follows. Mean pixels per dot is the total number of image pixels

Table 3 Relative spectrophotometer performances

\begin{tabular}{llll}
\hline & Gretag & $\begin{array}{c}\text { Datacolor } \\
\text { Imspector } \\
\text { Microflash }\end{array}$ \\
\hline Natural SD for constant colour $\Delta L^{*}>50$ samples (background noise) & 0.1349 & 0.0409 & 0.1170 \\
SD for 100\% tone blocks, stable printing machine trial $>$ 30 m sample & 0.2695 & 0.1694 & 0.5270 \\
Signal-to-noise ratio & $1.99: 1$ & $4.15: 1$ & $4.79: 1$ \\
\hline
\end{tabular}

Table 4 Expected output from dot feature analysis software (N/a, not applicable)

\begin{tabular}{|c|c|c|c|c|c|c|}
\hline Sample feature & Mean pixels per dot & Mean dot $\mathrm{d} x$ & Mean dot dy & White hole & High-frequency content & Inter-dot grey \\
\hline Hole size & $\mathrm{N} / \mathrm{a}$ & $\mathrm{N} / \mathrm{a}$ & $\mathrm{N} / \mathrm{a}$ & + & N/a & $\mathrm{N} / \mathrm{a}$ \\
\hline Dot size & ++ & ++ & ++ & + & $\mathrm{N} / \mathrm{a}$ & $\mathrm{N} / \mathrm{a}$ \\
\hline Boundary roughness & $\mathrm{N} / \mathrm{a}$ & $\mathrm{N} / \mathrm{a}$ & $\mathrm{N} / \mathrm{a}$ & ++ & +++ & -- \\
\hline Blotchiness & ++ & $\mathrm{N} / \mathrm{a}$ & N/a & + & ++ & --- \\
\hline Streaking & + & ++ & + & + & + & - \\
\hline
\end{tabular}


contained within each printed dot. Mean dot $\mathrm{d} x$ and mean dot $\mathrm{d} y$ are the mean $X$ - and $Y$-axis sizes respectively of a sample of around 200 dots. White hole is the percentage of image pixels that represents a small unprinted area encircled by a printed dot. High-frequency content is the amount of the image that may pass through a highpass convolution filter in order to reveal the presence of boundary roughness. Isolating each dot and examining the grey levels of the substrate between is used to detect ink bleed-through, a good indicator of a non-clean print. Unique values and combinations of values are produced for each processed print defect. Table 5 shows the actual output from the image-processing software; these results are presented in order to show that the image-processing software is performing as well as a human operator for the checking of dot features. Numerical output figures may be checked against the values given for a 'good' sample, as shown in the second column in Table 5. For example, boundary roughness would be expected to produce a greater high-frequency content. Reference between the first row of the sixth column (good) and the fourth row of the sixth column shows that the software outputs a higher figure, representing the increased highfrequency content. Correlation between expected results, based on manual viewing off line with a microscope, and the software output, later taken at full web speed with imaging data produced on line, is very good and acceptable for the industrial application.

\subsection{Integrated system}

A series of master samples were taken, and then process variables were deliberately altered to introduce process error. The KBS system was then used to guide the operator by making suggestions for process setting adjustments. The aim of these trials was to see whether the system was able to detect print faults and to offer recommendations to the operator to alter process settings, in order to return print quality to normal. It is important to remember that the data link between the machine and the KBS recommendations is based upon imaging data, in addition to web speed which is automatically monitored; thus viscosity and impression pressure, which may not be accurately measured, are inferred from imaging data. A summary of adjustment history results from a typical trial is shown in Table 6.

\section{CONCLUSIONS}

Thorough testing of the system validated the reliability of the imaging system in determining colour drift and dot features, and performance of the KBS was robust throughout. In machine trials, upwards of $9 \mathrm{t}$ of printed material was produced (tens of kilometres). In machine trials, many adjustments were made to the printing process and in all cases the imaging system and KBS were

Table 5 Actual output from dot feature analysis software

\begin{tabular}{lllrrr}
\hline Sample feature & Mean pixels per dot & Mean dot d $x$ & Mean dot dy & White hole & High-frequency content \\
\hline Good & 2138.29 & 61.4 & 57.7 & 0 & 0.0134 \\
Dot size & 4885.55 & 93.2 & 127.0 & 191 & 0.018 \\
Boundary roughness & 3224.86 & 75.7 & 80.4 & 1801 & 0.026 \\
Blotchiness & 3237.13 & 76.9 & 74.8 & 535 & 0.022 \\
Streaking & 2797.40 & 72.6 & 72.2 & 232 & 0.017 \\
\hline
\end{tabular}

Table 6 Process adjustment history (N/a, not applicable)

\begin{tabular}{llllll}
\hline $\begin{array}{l}\text { Master } \\
\text { sample }\end{array}$ & $\begin{array}{l}\text { Speed } \\
(\mathrm{m} / \mathrm{min})\end{array}$ & $\begin{array}{l}\text { Impression } \\
\text { pressure } \\
\text { (turns) }\end{array}$ & $\begin{array}{l}\text { Viscosity } \\
\text { (Foord) }\end{array}$ & $\begin{array}{l}\text { Suggestion to user } \\
\text { by KBS }\end{array}$ & Notes \\
\hline 1 & 123.88 & 3 & 15.5 & N/a & Master sample \\
& 92.71 & 3 & 15.5 & Increase speed & \\
& 111.46 & 3 & 15.5 & Increase speed & \\
& 123.07 & 1 & 15.5 & Increase pressure & Increase speed \\
& 122.83 & 3 & 15.5 & None: sample $=$ master & Successful adjustment \\
& 129.32 & 3 & 15.5 & N/a & Master sample \\
& 124.12 & 2.5 & 15 & Reduce pressure & Reduce pressure \\
& 124.12 & 4 & 15 & None: Sample $=$ master & Successful adjustment \\
& 124.12 & 3 & 15 & N/a & Master \\
& 124.12 & 2.5 & 20 & Increase viscosity & Reduce speed \\
& 122.97 & 3 & 19 & None: sample $=$ master & Successful adjustment \\
\hline
\end{tabular}


able to analyse drifts in printing process parameters and to alert the operator to make necessary changes in machine settings well before print quality had been allowed to drift to such a point that it was visible to the human eye. On-line automated inspection can thus save kilometres of scrap material, which may be generated during conventional manual process adjustment, as well as enabling more productive runs for printing with reduced downtime. Since this paper was written, the system has been developed commercially and is now marketed by Shelton Vision Systems Limited, as the PrintSpector.

\section{ACKNOWLEDGEMENTS}

The authors would like to thank industrial partners CWV Group Limited, RPC Containers Limited and Shelton Vision Systems Limited, for their support. This research was funded under the Engineering and Physical Sciences Research Council Innovative Manufacturing Initiative, Grant GR/M17358.

\section{REFERENCES}

1 Jackson, M. R., Brown, N., Parkin, R. M. and Peng, J. Intelligent processing of web based materials. In Mechatronics Forum (Mechatronics 2002), Drebbel Institute, University of Twente, The Netherlands, 2002.

2 Bohan, M. F. J., Claypole, T. C. and Gethin, D. T. Effect of process parameters on product quality of rotogravure printing. Proc. Instn Mech. Engrs, Part B: J. Engineering Manufacture, 2000, 214(B3), 205-219.

3 Bailey, J. Print quality is in the eye of the observer. Pulp Paper Can., 1999, 100(3), 32-33.

4 Anon. Colorimetry: Official Reccomendations of the International Commission on Illumination, CIE Publication 15, 1971 (Commission Internationale de l'Éclairage, Vienna, Austria).

5 Green, L. A. Vymura Colour Course, 1995 (Vymura Limited).

6 Brown, N., Peng, J., Jackson, M. R. and Parkin, R. M. Spectral imaging system for non-contact colour measurement. Optics Laser Technol., 2001, 33(2), 103-110.

7 Kim, D., Gregory, C. W., Smith, G. J. and Mohler, J. L. Immunohistochemical quantitation of androgen receptor expression using color video image analysis (vol 35, pg 2, 1999). Cytometry, 1999, 35(4), 376.

8 Ewing, R. P. and Horton, R. Quantitative color image analysis of agronomic images. Agron. J., 1999, 91(1), $148-153$.

9 Ewing, R. P. and Horton, R. Discriminating dyes in soil with color image analysis. Soil Sci. Soc. Am. J., 1999, 63(1), 18-24.

10 Bartleson, C. J., Bertrand, G. and Chalmers, A. N. Colorimetry, 2nd edition, 1986 (Commission Internationale de l'Éclairage, Vienna, Austria).

11 Brown, N., Jackson, M. R. and Parkin, R. Automatic gravure print feature determination at production speeds. Proc. Instn Mech. Engrs, Part B: J. Engineering Manufacture, 2003, 217(B8), 1101-1110.

12 Peng, J. B., Brown, N., Jackson, M. R. and Parkin, R. M. A fuzzy approach for relating dot features to printing process. In Proceedings of 2nd International Symposium on Printing and Coating Technology, University of Wales Swansea, 2000. 